\title{
polymers
}

ISSN 2073-4360

www.mdpi.com/journal/polymers

Article

\section{Calcite Biohybrids as Microenvironment for Stem Cells}

\section{Liliana Astachov ${ }^{1}$, Zvi Nevo ${ }^{2}$ and Razi Vago ${ }^{1, *}$}

1 Avram and Stella Goldstein-Goren Department of Biotechnology Engineering, Ben-Gurion

University of the Negev, Beer-Sheva 84105, Israel; E-Mail: eliliana@bgu.ac.il

2 Department of Human Molecular Genetics and Biochemistry, Sackler Faculty of Medicine,

Tel-Aviv University, Tel-Aviv 69978, Israel; E-Mail: zvinevo@ post.tau.ac.il

* Author to whom correspondence should be addressed; E-Mail: rvago@ bgu.ac.il;

Tel.: +927-86477181; Fax: +927-86472983.

Received: 20 February 2012; in revised form: 11 April 2012 / Accepted: 12 April 2012 /

Published: 23 April 2012

\begin{abstract}
A new type of composite 3D biomaterial that provides extracellular cues that govern the differentiation processes of mesenchymal stem cells (MSCs) has been developed. In the present study, we evaluated the chondrogenecity of a biohybrid composed of a calcium carbonate scaffold in its calcite polymorph and hyaluronic acid (HA). The source of the calcite scaffolding is an exoskeleton of a sea barnacle Tetraclita rifotincta ( $T$. rifotincta), Pilsbry (1916). The combination of a calcium carbonate-based bioactive scaffold with a natural polymeric hydrogel is designed to mimic the organic-mineral composite of developing bone by providing a fine-tuned microenvironment. The results indicate that the calcite-HA interface creates a suitable microenvironment for the chondrogenic differentiation of MSCs, and therefore, the biohybrid may provide a tool for tissue-engineered cartilage.
\end{abstract}

Keywords: calcium carbonate; mesenchymal stem cells (MSCs); chondrogenesity; hyaluronic acid (HA)

\section{Introduction}

A tissue engineering approach to the regenerative medicine of bone and cartilage entails the use of grafts that contain both scaffold as supporting material and cultured cells. Choosing the most suitable scaffold material may seem to be a complicated task because the requirements dictated by the 
application are difficult to fulfill simultaneously. These requirements include biocompatibility and support of cellular adhesion, expansion, and differentiation to produce engineered tissue with mechanical properties similar to those of the host tissue. In addition, the scaffold should also allow for new 3D tissue formation by supporting tissue spatial organization by enabling sufficient nutrient supply to, and waste elimination from, the cells in the tissue [1,2].

Scaffold material choice, therefore, is crucial to tissue engineering. In addition to its foundational role, the scaffold must stimulate precise cellular responses and control cellular- specific biological recognition $[3,4]$, i.e., it must be biologically active. The signals the cells receive from the environment (the scaffold is a part of the cells microenvironment) in fact determine whether the scaffold adopts the functional properties of the integrated tissue. Moreover, the extracellular matrix (ECM), an additional active environment, interacts with the cells and holds a key to in vitro manipulations. Indeed, the stem cell's microenvironment appears to be the critical factor for determining lineage specification. Mesenchymal stem cells (MSCs) cultured in vitro display multipotential behavior in response to changes in local environment [5-7].

Biomaterials can typically be grouped according to synthetic polymers, ceramics, and natural materials. Synthetic polymers, which are biodegradable and easy to process, include among many others, polylactic/polyglycolic acids and their combination, polycaprolactone [8,9]. However, synthetic polymers lack biological recognition, and cellular responses to them are weak. Ceramics include a broad range of inorganic and non-metallic compounds, from the completely inert to those that develop strong interfacial bonds and can even sustain significant mechanical forces [9,10]. This group includes bioactive glasses, glass-ceramics, and calcium phosphate compounds such as apatites. Composite biomaterials, created by combining representatives from two or more of these categories, offer certain advantages - such as control over material properties and a high potential for improved performance - compared with homogenous biomaterials [11].

The material used in this research is a composite (hybrid) material whose constituent components are both natural biomaterials. Natural calcium carbonate in a calcite polymorph prepared from the exoskeleton of sea barnacles was combined with the natural glycosaminoglycan hyaluronic acid (HA) to study a composite material that supports a suitable microenvironment for the chondrogenic differentiation of MSCs.

The use of natural coral graft substitutes of marine origin began in the early 1970s and was successful both in animals and in humans (for review see [12,13]). The coral exoskeleton, made of calcium carbonate in aragonite polymorph, has a structure similar to that of cancellous bone. These scaffolds have since been shown to be biocompatible, osteoconductive, and biodegradable [14-16]. A calcite polymorph of calcium carbonate from natural limestone was used as a bone substitute in vivo in rabbits [17]. Calcite, transformed by heating aragonite from natural coral, has been tested in vitro where it was shown to be osteogenic [18].

Marine calcium carbonate scaffolds can also be made from the exoskeleton of barnacles, a widely distributed group of marine sessile crustaceans. The exoskeleton of the barnacle Tetraclita rufotincta consists mainly of calcite with a small number of specialized proteins. This mineralized skeleton forms a unique honeycomb structure covered by nacre shell plates. The scaffold made from the barnacle exoskeleton of $T$. rifotincta was recently tested for its biocompatibility in our laboratory $[19,20]$. The 
study demonstrated that the scaffold promotes chondrogenic differentiation of MSCs after the cells were seeded onto this biomaterial.

Hyaluronic acid (HA) is a natural glucosaminoglycan, that plays an important role during embryonic development [21-23] and that initiates the signal pathways essential for MSC chondrogenic differentiation [24-27]. In the tissue engineering field, HA has been utilized to repair defects of the skin or of the musculoskeletal system, including cartilage, bone, ligament, and intervertebral discs [28-33]. To decrease it's in vitro and in vivo degradation rates, HA usually undergoes chemical modification before being used in tissue engineering [34-37]. That chemical modification, however, typically impedes the biocompatibility of, and cell attachment to, the scaffold [38,39]. In this work, we investigated the advantages of using unmodified, high molecular weight HA combined with a natural 3D calcite scaffold. Chondrogenesis was induced in the cells cultured on the composite biomaterial, as indicated by their increased accumulation of chondrogenic matrix compared to the tissue cultured on the calcite scaffold without added HA. Furthermore, the tissue cultured in the presence of HA showed a long-term (up to six weeks), stable chondrogenic phenotype while the tissue cultured without HA expressed osteogenic markers after three weeks of culturing. The goals of this study were to analyze a novel, biphasic, bioactive material that provides a microenvironment suitable for the chondrogenic differentiation of MSCs. The resulting hybrid composite, which exhibited characteristics of a bioactive supporting material together with controlled molecular signaling activity, has multiple applications in cartilage tissue engineering.

\section{Experimental Section}

\subsection{Experiment Design}

To evaluate chondrogenecity of the complex biohybrid, the following experimental groups were designed and analyzed:

Calcite (control) group-MSCs were seeded on the calcite scaffold and cultured in a basic DMEM medium;

Calcite-HA group-MSCs were seeded on the calcite scaffold and cultured in a basic DMEM medium supplemented with HA at the concentration described in the section below on cell culturing;

Gold calcite group - the calcite scaffold was coated by a nano-scale layer of gold prior to MSCs seeding, and the cells were cultured in a basic DMEM medium. Gold coating is used to neutralize a calcite chemical effect on the cultured MSCs, thereby preserving complex 3D topography of the scaffold;

Gold calcite-HA group - the calcite scaffold was coated by a nano-scale layer of gold prior to MSC seeding, and the cells were cultured in a basic DMEM medium supplemented with HA at a concentration of $0.5 \mathrm{mg} / \mathrm{mL}$. Gold coating is designed to neutralize a calcite chemical effect on the cultured MSCs, thereby preserving complex 3D topography of the scaffold.

\subsection{Scaffold Preparation}

Specimens of $T$. rufotincta were collected from the upper belt of the shallow seawater zones adjacent to the Interuniversity Institute for Marine Science (IUI) of the Red Sea, Eilat, Israel. The 
average overall diameter of the shells included in this study was $4.5-5.0 \mathrm{~cm}$. The animals were removed from the shells, which were subsequently bleached in $2 \%$ sodium hypochlorite solution for $30 \mathrm{~min}$. Hypochlorite solution residue was washed away with distilled water (DW). The shells were then cut into $5 \mathrm{~mm}$ thick samples that were polished to a thickness of approximately $0.5 \mathrm{~mm}$ and an area of $0.5 \mathrm{~cm}^{2}$ using an $8 "$ grinder machine (model SPT 900). To produce the gold-covered scaffolds, polished samples were placed in a Veeco VE, VP-776 evaporator and coated with a $300 \AA$ gold layer under a constant chamber pressure of $10^{-6}$ Torr at a rate of $3 \AA$ s. The samples were then rinsed with $70 \%$ ethanol. Prior to cell seeding, the natural and gold-coated scaffolds were sterilized by autoclave $\left(121^{\circ} \mathrm{C}, 30 \mathrm{~min}\right)$ and then dried overnight at $60^{\circ} \mathrm{C}$.

\subsection{Cell Culturing}

The mesenchymal mouse cell line ATCC/CRL 12424 (passage 4) was seeded at a concentration of 10,000 cells per scaffold for further study. Cells were allowed to adhere for $15 \mathrm{~min}$, and then culture medium was added. The basic culture medium contains Dulbecco modified Eagle's medium (DMEM) (Biological Industries, Israel) supplemented with $4.5 \mathrm{~g} / \mathrm{L} D$-glucose, $1.5 \mathrm{~g} / \mathrm{L}$ sodium bicarbonate (Sigma), $1 \mathrm{mM}$ sodium pyruvate (Biological Industries, Israel), 10\% (v/v) fetal calf serum (Biological Industries, Israel), 1\% L-glutamine (Biological Industries, Israel), and 1\% PSN antibiotic solution (Gibco, USA). Unless noted otherwise, the conditions for added HA comprised supplementing the basic medium with HA (MW 3000kD, BTG LTD, Israel) at a concentration of $0.5 \mathrm{mg} / \mathrm{mL}$. Cells were cultured at $37{ }^{\circ} \mathrm{C}$ in a humidified $5 \% \mathrm{CO}_{2}$ incubator. The medium was replaced every two days.

\subsection{Scanning Electron Microscopy (SEM) Analysis}

MSC cultures were rinsed with saline and fixed with fixative containing 2\% paraformaldehyde in DW and $2.5 \%$ glutaraldehyde in $0.1 \mathrm{M}$ buffer phosphate. After fixation, the samples were washed and subjected to graded ethanol dehydration, followed by final dehydration in hexamethyldisilazane (HMDS) (Electron Microscopy Sciences, PA). Then the samples were gold coated with a sputter-coater at $15 \mathrm{~mA}$ for $60 \mathrm{~s}$. Samples morphologies were visualized using scanning electron microscopy (SEM) (JEOL, JSM-5610-LV).

\subsection{Cell Proliferation Assay}

Cell proliferation was measured by an XTT cell proliferation assay kit (Biological Industries, Israel) according to the manufacturer's instructions. A calibration curve was plotted using counted MSCs. Tests were performed in triplicate and the average cell number on each scaffold was calculated using the calibration curve.

\subsection{GAG Quantification}

For GAG quantification after 7, 14, and $21 \mathrm{~d}$, scaffolds containing MSCs were first digested with a papain solution comprising $0.01 \mathrm{M} L$-cysteine and $0.05 \%$ papain dissolved in phosphate buffered EDTA adjusted to a $\mathrm{pH}$ of 6.5 , for $24 \mathrm{~h}$ in a $60{ }^{\circ} \mathrm{C}$ water bath. Following digestion, $50 \mu \mathrm{L}$ from each sample was added to a 96-well plate and $200 \mu \mathrm{L}$ of dimethylmethilene blue (DMMB) solution was 
added to each well. Absorbance was read at $525 \mathrm{~nm}$. Chondroitin sulfate (C-8529, Sigma-Aldrich Israel) at concentrations of $100-0.75 \mu \mathrm{g} / \mathrm{mL}$ was used to build a calibration curve. GAG quantities were normalized to cell number as measured using the Alamar Blue ${ }^{\mathrm{TM}}$ Cell Proliferation Indicator prior to digestion by papain.

\subsection{In Vitro Chondrogenic Differentiation Assay}

An assay based on a GAG distribution analysis was developed to visualize the effect of the addition of HA on MSCs cultured on a calcite scaffold. About 5000 cells were seeded on the calcite samples in Petri dishes, one sample per dish, and cultured for six weeks. The GAG accumulation process in the cell culture was visualized by safranin $\mathrm{O} /$ fast green staining, which is specific for GAGs. In the safranin $\mathrm{O} /$ fast green combination, the balance between the two stains reveals the chondrogenic character of the culture: the fast green stained the cell culture pale green, and safranin $\mathrm{O}$, which is specific for the cartilage tissue, stained proteoglycans (PG) and glycosaminoglycans (GAGs) a pink-red color. All photographs were taken at the same light intensity and exposure time to ensure fixed conditions and therefore to enable subsequent color image analyses. The images were analyzed for the size of the area colored by safranin $\mathrm{O}$ and for its digital color intensity (i.e., the overall number of colored pixels for the image). For the analysis, the area colored by safranin $\mathrm{O}$ was defined manually, after which the image was stacked to RGB colors, and the red color intensity was automatically calculated within the defined area. The analysis was performed in at least six duplicates using the NIH-developed open source software ImageJ.

\subsection{Immunofluorescence Analysis}

Samples were rinsed gently with PBS and fixed with buffered $4 \%$ glutaraldehyde solution for $10 \mathrm{~min}$ at $4{ }^{\circ} \mathrm{C}$. Fixed samples were rinsed three times with PBS (5 min per wash) and incubated in blocking solution containing 10\% normal serum in PBS for $1 \mathrm{~h}$. The samples were placed in a humidified chamber (overnight) and stained with goat polyclonal Immunoglobulin G (IgG) against type I collagen (Santa Cruz Biotechnology, USA), or goat polyclonal IgG against type II collagen (Santa Cruz Biotechnology, USA), diluted to a 1:300 ratio with PBS at $4{ }^{\circ} \mathrm{C}$. The samples were washed three times (5 min per wash) with PBS and then incubated in a 1:200 diluted solution of donkey anti-goat IgG fluorescein isothiocyanate (FITC) conjugated affinity purified antibody (Santa Cruz Biotechnology, USA) or rhodamine red-X-conjugated affiniPure donkey anti goat IgG $(\mathrm{H}+\mathrm{L})$ (Jackson Immunoresearch Laboratories, INC., USA) in PBS for $60 \mathrm{~min}$ at room temperature. After the secondary antibodies were removed, the samples were again washed three times with PBS and photographed using an inverted fluorescence microscope (Nikon, Eclipse TE300) with FITC or rhodamine filters.

\subsection{Gene Expression}

On days 7,14 , and 21 , biolattices $(\mathrm{n}=2-3)$ were transferred to $1.5 \mathrm{~mL}$ centrifuge tubes and washed with cold PBS. Total RNA was isolated using a power SYBR green GEx Cells-to-Ct kit (Invitrogen Life Science, USA) according to the manufacturer's instructions. First-strand cDNA was subsequently 
synthesized in a $50 \mu \mathrm{L}$ reaction mixture from $1 \mu \mathrm{g}$ total RNA using the same kit. The sample that did not contain transcription enzyme was used as the negative control to test for genomic contaminations.

Table 1. Primers used for relative quantification real-time PCR (F-forward, R-reverse).

\begin{tabular}{llll}
\hline Gene & & Sequence & Reference Sequence \\
\hline GAPDH & F & 5'-CCTGGAGAAACCTGCCAAGTAT-3' & NM_008084 \\
& $\mathrm{R}$ & 5'-GATGCCTGCTTCACCACCTT-3' & \\
Colla2 & $\mathrm{F}$ & 5'-CCAAGAAGACATCCCTGAAGTCA-3' & NM_000089 \\
& $\mathrm{R}$ & 5'-TGCACGTCATCGCACACA-3' & \\
Col2al & $\mathrm{F}$ & 5'-CGAGATCCCCTTCGGAGAGT-3' & NM_001844 \\
& $\mathrm{R}$ & 5'-CTGCCCCTTTGGCCCTAAT-3' & \\
Sox9 & $\mathrm{F}$ & 5'-ACCAGTACCCGCATCTGCAC-3' & NM_011448 \\
& $\mathrm{R}$ & 5'-CTCGTTCAGCAGCCTCCAG-3' & \\
Runx2 & $\mathrm{F}$ & 5'-GAGTCATTTAAGGCTGCAAGCA-3' & NM_001145920 \\
& $\mathrm{R}$ & 5'-CGGTGTCACTGCGCTGAA-3' & \\
CD44 & $\mathrm{F}$ & 5'-CCTCAGCCCCTCCTGAAGA-3' & NM_000610 \\
& $\mathrm{R}$ & 5'-CGAGTACCATCACGGTTGACA-3' & \\
\hline
\end{tabular}

The PCR reaction was carried out in a final volume of $20 \mu \mathrm{L}$, which contained $2 \mu \mathrm{L}$ of cDNA template, gene-specific primer sets (Table 1), and SYBR Green (Invitrogen Life Science, USA) according to the manufacturer's protocol. The primer sets were designed using primer express software (Applied Biosystems). Thermal cycling was carried out using a StepOnePlus ${ }^{\mathrm{TM}}$ Real-Time PCR System (Applied Biosystems, USA) and mRNA expression levels of target genes were analyzed using the $\Delta \Delta \mathrm{CT}$ method [40], with glyceraldehide-3-phosphate dehydrogenaze (GAPDH) as the housekeeping gene. The results are presented as the mean of triplicates experiments from two independent experiments (error bars represent SD).

\subsection{Statistical Analysis}

Quantitative data were presented as means \pm standard deviation. The independent sample $t$-test was used to detect statistically significant differences in two groups; a two-way repeated measure of ANOVA was used to compare more than two groups over time. Statistical significance was defined as $* p<0.05, * * p<0.01$, and ${ }^{\#} p<0.001$.

\section{Results and Discussion}

\subsection{Effect of HA Concentration on MSC Proliferation}

The XTT cell proliferation test was performed to evaluate the effect of HA concentrations on MSC proliferation in the 3D system. Five different concentrations of HA $(0.1,0.5,1,2$, and $4 \mathrm{mg} / \mathrm{mL})$ were selected for this study, in which the control cell culture was grown without the addition of HA. As shown in Figure 1a, the cells cultured in the presence of HA in the medium show dose-dependent responses compared to control cell cultures. At all concentrations, the presence of HA increased cell proliferation at days 4-7. After day 7, the addition of HA had an inhibitory effect on cell proliferation, while concentrations above $2 \mathrm{mg} / \mathrm{mL}$ dramatically reduced the number of cells. The HA concentration 
of $0.5 \mathrm{mg} / \mathrm{mL}$ was chosen as optimal for further analyses due to its stable effect on the proliferation of MSCs: at this concentration, total cell numbers rapidly increased after seeding and peaked at day 7 , after which the number of cells remained statistically the same (Figure 1b). Our evaluation of the effect of HA concentrations on MSCs indicates that HA affected MSC proliferation in a dose-dependent manner. Data in the literature shows that the addition of small concentrations of low molecular weight HA stimulates MSC proliferation [42,43], while the same concentration of high molecular weight HA appears to inhibit the cells $[44,45]$. Our experiments with high molecular weight HA in a $2 \mathrm{D}$ system did not show any significant effect on MSC proliferation (data not shown) while cells cultured on a calcite scaffold in a 3D system in the presence of HA of various concentrations displayed a reduction in cell number. Indeed, concentrations of HA above $2 \mathrm{mg} / \mathrm{mL}$ significantly inhibited MSCs cultured on calcite, and in fact, HA seems to be cytotoxic at high concentrations. In contrast, low concentrations of HA $(0.1-0.5 \mathrm{mg} / \mathrm{mL})$, after the initial (during the first week) accelerated proliferation of MSCs, appear to maintain the cells at the same level of proliferation activity for up to three weeks, while MSCs cultured on calcite without HA continued to proliferate. The HA concentration of $0.5 \mathrm{mg} / \mathrm{mL}$ has thus been recommended as optimal for studying its effect on MSC differentiation. We suggest that at this concentration, HA accelerates MSC proliferative activity subsequent to MSC chondrogenic differentiation.

Figure 1. Cell proliferation test $(n=6)$ over a 21 day period, measured by the XTT method. (a) Effect of hyaluronic acid (HA) concentration on mesenchymal stem cells (MSCs) proliferation. The cells in the culture without HA added to the media gradually increased in number at an approximately constant rate. Concentrations of $1 \mathrm{mg} / \mathrm{mL}$ and above were toxic for the cells. The concentration of $0.5 \mathrm{mg} / \mathrm{mL}$ was considered to be optimal for the culture; (b) Proliferation kinetics of MSCs in calcite, calcite-HA, gold calcite, and gold calcite-HA groups. In the HA-calcite culture, the number of cells reached a maximum at 7 day, showing no statistical difference at either 14 or 21 day, while in the calcite, gold calcite, and gold calcite-HA groups, cell counts increased over the test period. Data are represented as the means; error bars represent the standard deviations.
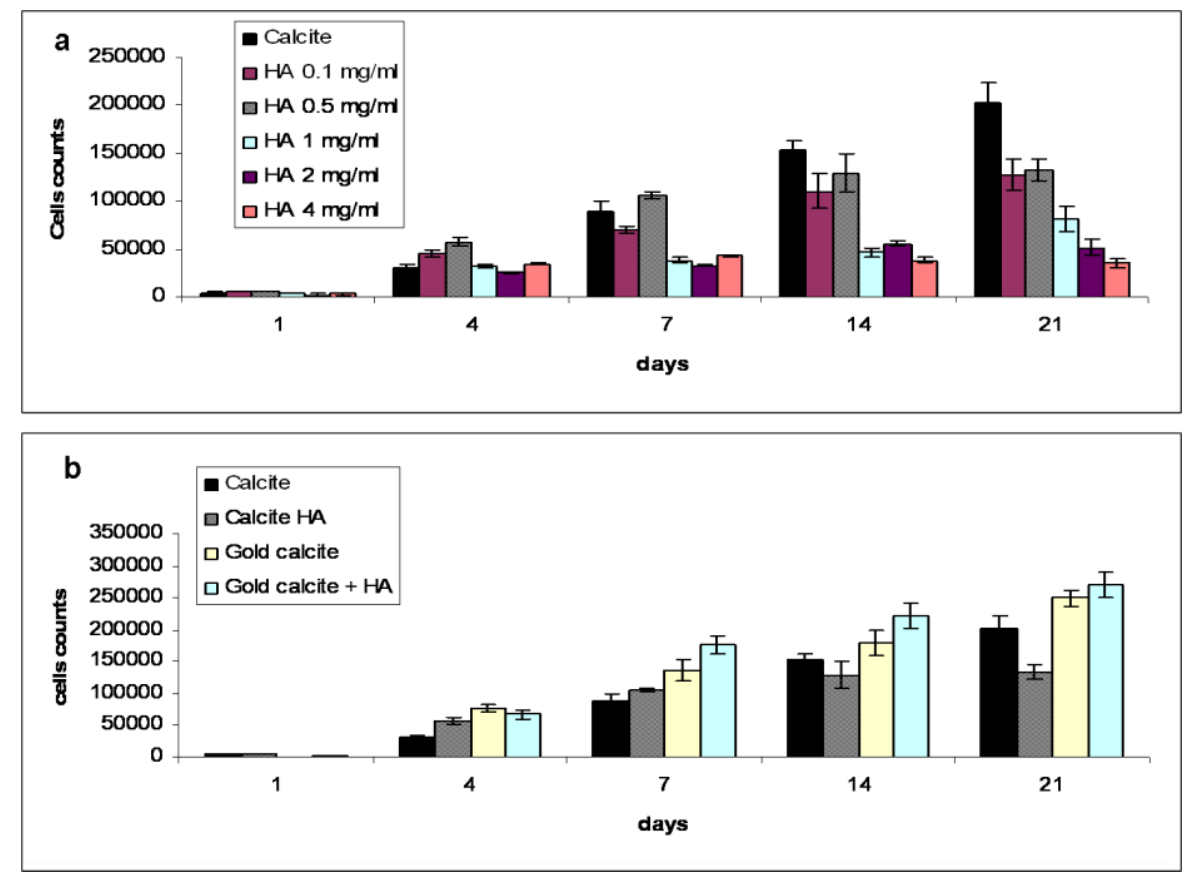


\subsection{Cell Proliferation Kinetics in Calcite, Calcite-HA and Gold Calcite Groups}

Figure 1B presents cell proliferation kinetics in all groups during the test period as measured by the XXT method. The graph shows how cell numbers changed from an initial (at day 0) density of 10,000 cells per scaffold on both the calcite and gold calcite scaffolds with and without HA, thus revealing the effects of $\mathrm{HA}$ and calcite independently on cell proliferation rates. The proliferation kinetics of the cells cultured on calcite were significantly affected by the addition of HA. The number of the cells cultured in the presence of HA reached a maximum at $7 \mathrm{~d}$, showing no statistical difference at either 14 or $21 \mathrm{~d}$. The cell count for cultures on calcite in the absence of HA, however, increased linearly during the entire experiment. In the gold calcite and the gold calcite-HA cultures, cell numbers gradually increased during the test period.

\subsection{SEM Analysis}

MSC adhesion, morphology and distribution were observed using SEM. Figure 2 shows SEM micrographs taken at days $1(\mathbf{a}, \mathbf{c}), 4(\mathbf{b}, \mathbf{d})$, and $21(\mathbf{e}, \mathbf{f})$. The attachment and morphology of MSCs on calcite were affected by the presence or absence of HA in the medium. Compared with those containing only calcite, cultures of calcite with HA promoted initial cell attachment (Figure 2a,c). As growth continued, the cells cultured on the calcite-HA complex had spherical morphologies characteristic of chondrocytes [41] and well-developed extracellular matrices (Figure 2g,h). SEM evaluation demonstrated that the MSCs cultured in the presence of HA underwent morphological changes into chondrogenic-like phenotypes, about 2 weeks after the culture was begun. Cells became round and exhibited extensive, highly organized extracellular matrix while the cells cultured in the absence of HA on the calcite scaffold assumed more flattened, fibroblast-like morphologies, were embedded in the fine extracellular matrix, and they became over-confluent after three weeks (Figure 2e,f).

Figure 2. SEM micrographs of MSCs on calcite scaffold $1(\mathbf{a}, \mathbf{c}), 4(\mathbf{b}, \mathbf{d})$ and $14 \mathrm{~d}(\mathbf{e}, \mathbf{g}, \mathbf{f}$, h) after cell seeding. Cells were grown in the absence $(\mathbf{a}, \mathbf{b}, \mathbf{e}, \mathbf{f})$ or the presence $(\mathbf{c}, \mathbf{d}, \mathbf{g}, \mathbf{h})$ of HA in the medium. Magnifications: $\mathbf{a}, \mathbf{b}, \mathbf{c}, \mathbf{d} \times 500 ; \mathbf{e}, \mathbf{g} \times 1000 ; \mathbf{f}, \mathbf{h} \times 3000$.
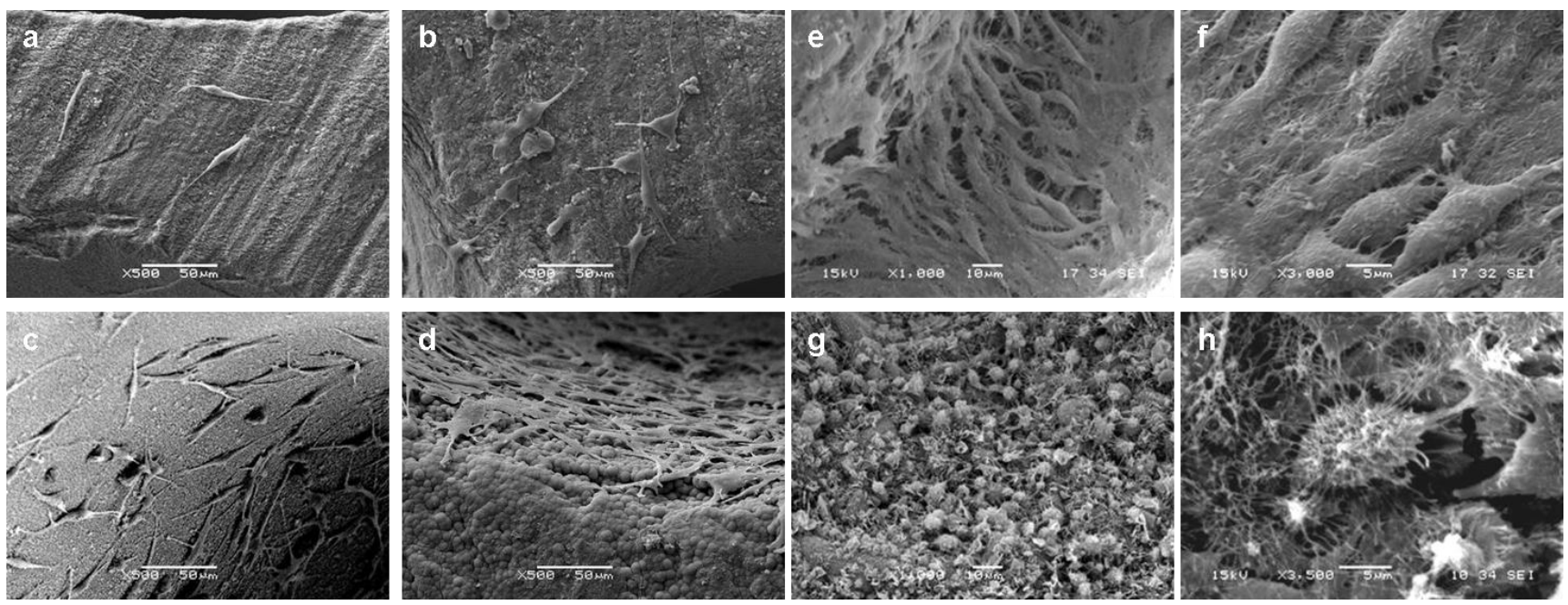


\subsection{Sulfated GAGs Quantification}

Quantification of sulfated GAGs for the cells cultured in the calcite and calcite-HA cultures reveals that GAG accumulation substantially increased in the presence of HA compared with the cells cultured on calcite alone (Figure 3). For the calcite group, GAG accumulation in the ECM increased during the first two weeks, after which it remained at the same level. In the calcite-HA group, three weeks after beginning the culture, the GAG content was more than twice that of the calcite group. For the gold-coated groups, the addition of HA to the medium had very little effect on GAG accumulation, in either group (gold calcite without or with HA), such that the cells produced scant amounts of the GAGs compared with the calcite group.

Figure 3. Analysis of sulfated glycosaminoglycan (GAG) accumulation in tissues evaluated by DMB assay $(n=6)$. GAG amounts were evaluated at 7,14 , and $21 \mathrm{~d}$ in the calcite, calcite-HA, gold calcite, and gold calcite-HA groups and represented in $\mu \mathrm{g}$ GAGs per 100,000 cells. GAG release was evaluated after papain digestion of the tissues. The statistical analysis revealed significant differences between the calcite and other groups at 14 and $21 \mathrm{~d}$. Data are represented as the means; error bars represent the standard deviations.

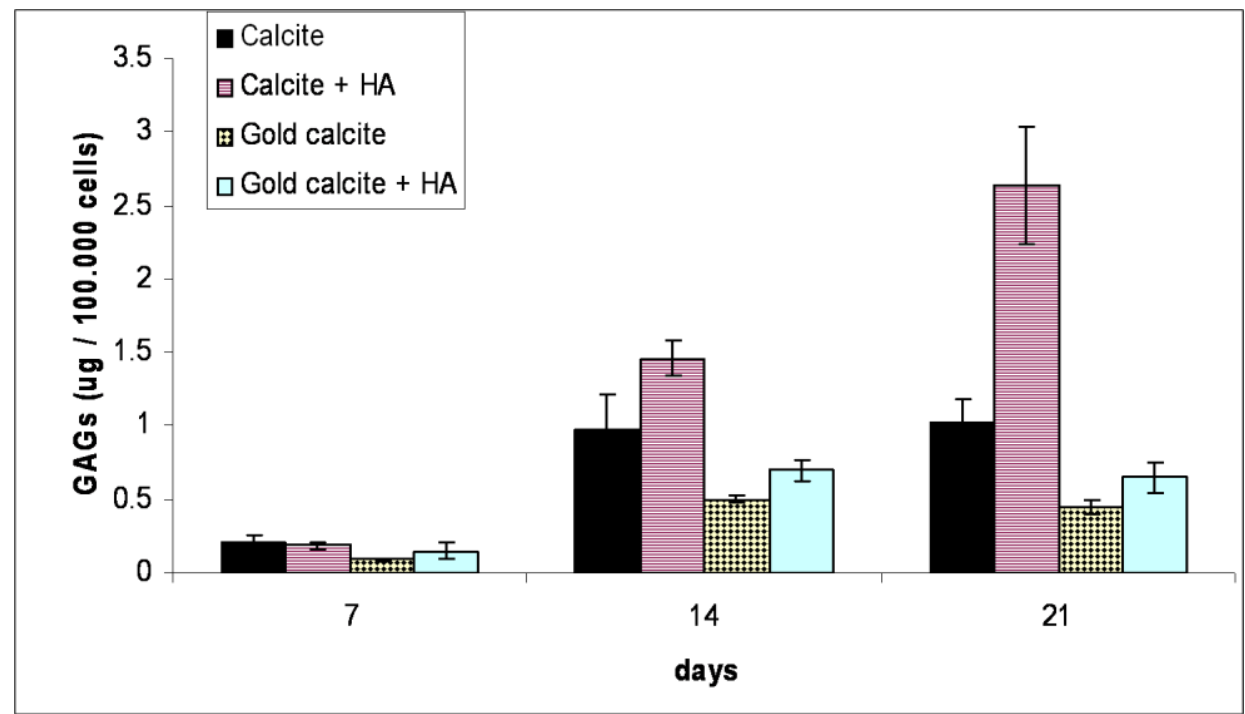

\subsection{In Vitro Chondrogenic Differentiation Assay}

Long-term (up to six weeks) GAG distribution in the ECM of the cultured cells was visualized using a newly developed assay (Figure 4). Digital analysis of the images (Figure 4b,c) revealed that cells grown on the calcite scaffold had the potential to differentiate toward the chondrogenic lineage, but in the long-term, the cultured cells lost their chondrogenic character. Maintaining a steady supply of HA to the medium increased the tendency for GAG molecules to be synthesized. Cells grown on the gold coated calcite without added HA showed no indications of chondrogenecity during the entire test period. Results comparable to those of the control (calcite) group were obtained for cells grown on the gold coated calcite with added HA. 
Figure 4. Chondrogenic differentiation of MSCs in calcite, calcite-HA, gold calcite, and gold calcite-HA cultures as revealed by safranin O/fast green staining at 7, 14, 21, 28, 35, and $42 \mathrm{~d}$. (a) Images of stained cell cultures growing on the small calcite and gold calcite particles in the presence or the absence of HA in the medium. Bar $=1 \mathrm{~mm}$; (b) Digital analysis of the area colored by safranin $\mathrm{O}(\mathrm{n}=6)$; (c) Digital analysis of the color intensity $(n=6)$. Data are represented as the means; error bars represent the standard deviations.

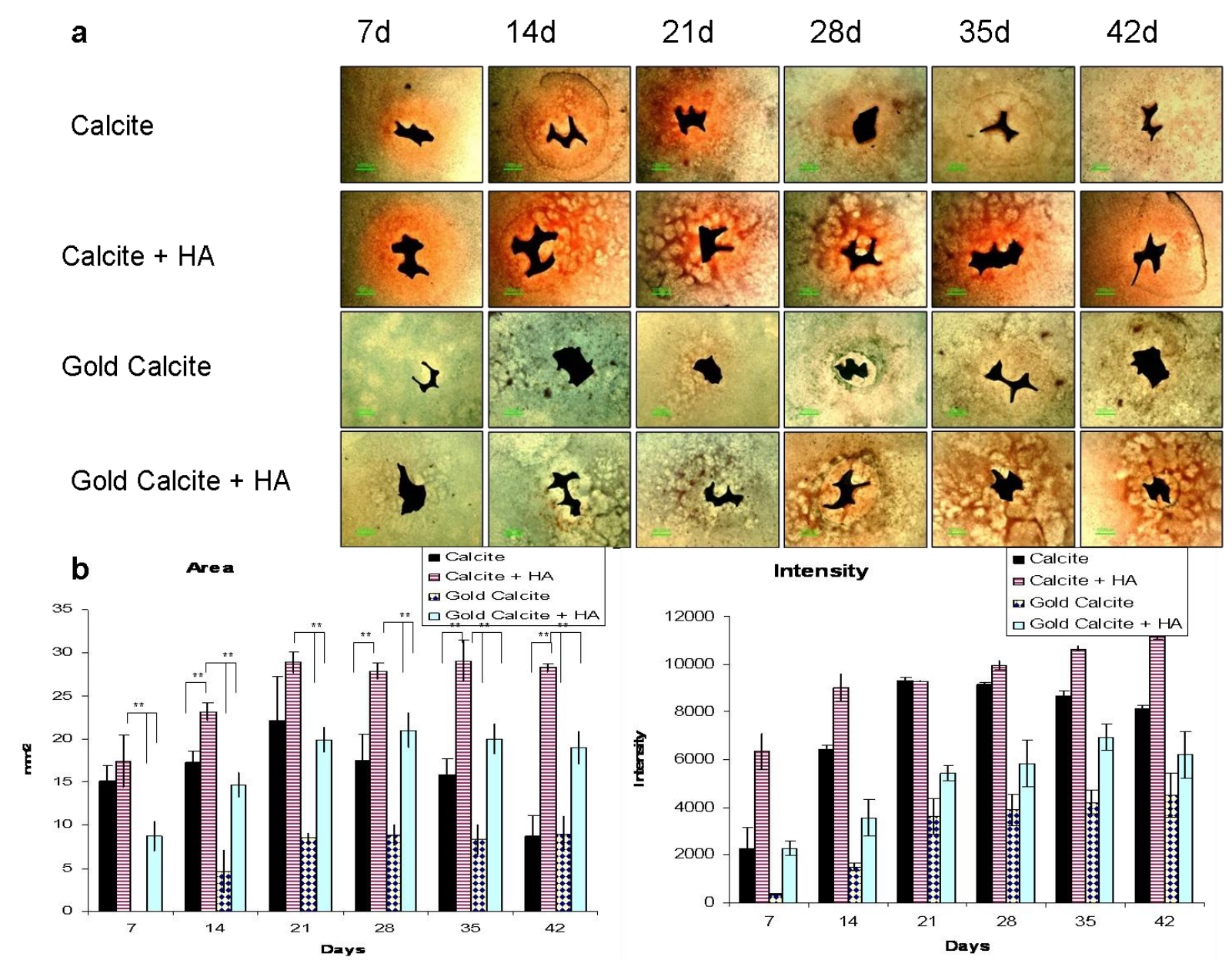

The results in supplement with the sulfated GAGs quantification and SEM analysis clearly indicate that the tissue underwent chondrogenic differentiation in the calcite-HA culture at day 14. GAG expression in the calcite, gold, and gold-HA groups was significantly lower than in the calcite-HA culture for the entire length of the experiment, suggesting that the chondrogenic potential exists in the combined calcite-HA complex and that it is not restricted to the calcite or the gold-HA cultures. Likewise, the results of the chondrogenecity assay (Figure 4) demonstrate that the cells grown on the calcite scaffold have the potential to chondrogenically differentiate. The data showed that cells cultured in the calcite-HA tissue displayed strong chondrogenic tendencies as they underwent chondrogenic differentiation, and they maintained the chondrogenic phenotype in long-term cultures. Thus, in the case of calcite, the addition of HA supported and promoted the chondrogenic potential of the calcite biomaterial. 


\subsection{Gene Expression}

Figure 5. Changes in the expression levels of genes secreted by MSCs cultured in the calcite, calcite-HA, gold calcite and gold calcite-HA systems. The gene expression profiles of the genes CD44 (a), Col2al (collagen type II) (b), Sox9 (c), Colla2 (collagen type I) (d) and Runx2 (e) were analyzed by real-time PCR after 7, 14, and $21 \mathrm{~d}$ of culturing. GAPDH was the housekeeping gene. Data are represented as the means; error bars represent the standard deviations.

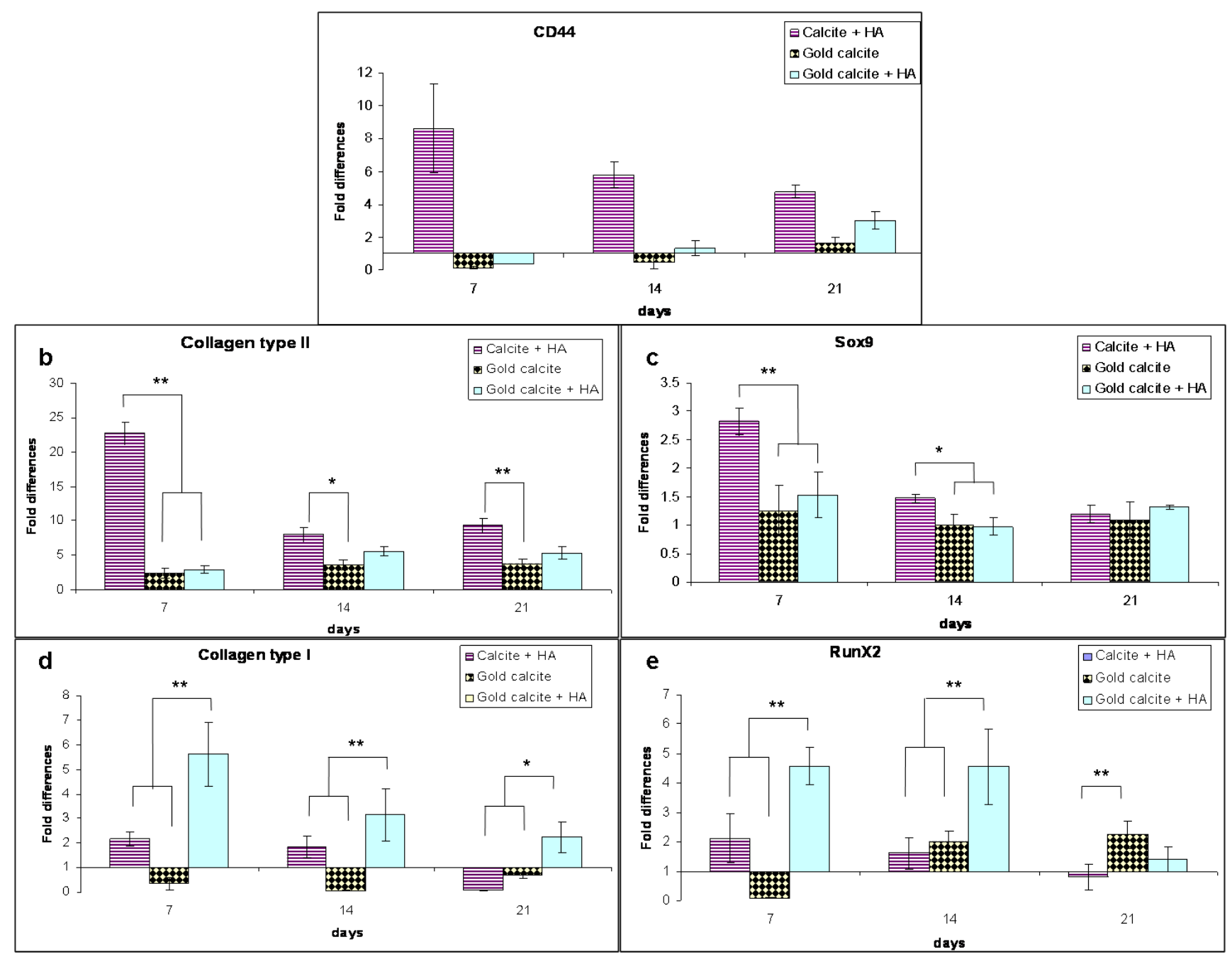

A fold change analysis of gene expression in the calcite-HA, gold calcite, and gold calcite-HA was compared to that in the calcite (control) culture. A primary HA receptor CD44 was expressed at significantly higher levels in the calcite-HA culture, where initially its expression increased approximately eightfold by about day 7 but then gradually decreased fourfold by day 21 (Figure 5a). CD44 gene expression in the gold and gold-HA cultures was markedly lower than in the calcite culture for the first two weeks, but at 21 day it increased slightly. There were no significant differences between the gold calcite and gold calcite-HA groups, apart from the slightly higher expression of CD44 on day 21.

Expression of the chondrogenic genes collagen type II Col2al and Sox9 in the calcite-HA culture was higher at day 7 and exhibited a decreasing trend over the test period (Figure 5b,c). By day 7 , expression of the collagen type II gene was strongly upregulated (23-fold) while Sox 9 gene expression 
increased approximately threefold. For the Col2aland Sox9 genes, we did not find any significant difference between the gold calcite and gold calcite-HA cultures. The expression of both genes increased over the test period and at day 21 for $\operatorname{Sox} 9$ no significant differences were found between all the groups.

Expression of the osteogenic genes RunX2 and collagen type I increased significantly during the test period in the gold calcite-HA culture with the exception of day 21 for the RunX2 gene, for which we did not find any significant differences relative to the control group (Figure 5d,e). For the calcite-HA culture, the expression of RunX2 and collagen type I genes did not differ statistically from the calcite culture. For the gold group, collagen type I increased approximately twofold on days 7 and 14 and showed no difference on day 21. RunX2 gene expression for this group decreased significantly in the early stage (day 7), but by days 14 and 21 , it had increased twofold.

Gene expression analysis by relative RT-PCR revealed that expression of the primary HA receptor CD44 was affected by the presence of HA in calcite-HA culture but not in the gold calcite-HA culture (Figure 5a). The CD44 receptor is involved in multiple cellular mechanisms related to ECM-activated signaling and its expression increased with increasing cell proliferation rate $[26,27,46]$. Indeed, from the proliferation test (Figure 1) it is clear that during the first week, the cells in the calcite-HA culture exhibited an enhanced proliferation rate relative to those of the other groups. After the first week, however, both proliferation rate and CD44 gene level decreased in the calcite-HA culture. Activation of the receptor by HA is achieved via precise spatial folding of the HA chains $[47,48]$, and we hypothesize that at the calcite-HA interface, the HA chains adopt a spatially orientated molecular conformation that is necessary to activate the CD44 receptor, a hypothesis supported by our previous investigation [20].

The expression of Sox9, which reaches high levels after mesenchymal condensation and is completely downregulated in hypertrophic chondrocytes, is important for chondrogenic differentiation [49-51]. The collagen type II Col2al gene is a direct target of Sox9 [52]. The expressions of these two cartilage-specific factors in the calcite-HA culture were amplified at day 7 (23-fold for Col2al and 2.8-fold for Sox9), suggesting that during the first week of culture, the MSCs committed mainly to a chondrocytic phenotype (Figure 5b, c). In contrast, the expression of RunX2, which is required for osteoblastic differentiation and expressed in the final stages of hypertrophic chondrocytes [53], reached high levels in the gold calcite-HA culture, and the data correlated well with expression of the osteoblast-specific marker collagen type I.

\subsection{Immunohistochemical Staining}

Immunohistochemistry analyses of $\mathrm{N}$-Cadherin (Figure 6) for calcite and calcite-HA cultures at days 7 (Figure 6a) and 14 (Figure 6b) revealed that the expression of $N$-cadherin in the calcite-HA culture increased on both days relative to the expression of the protein in the calcite group. 
Figure 6. Immunohistochemical staining of the expression of $N$-cadherin in the calcite and calcite-HA culture after 7 and $21 \mathrm{~d}$.

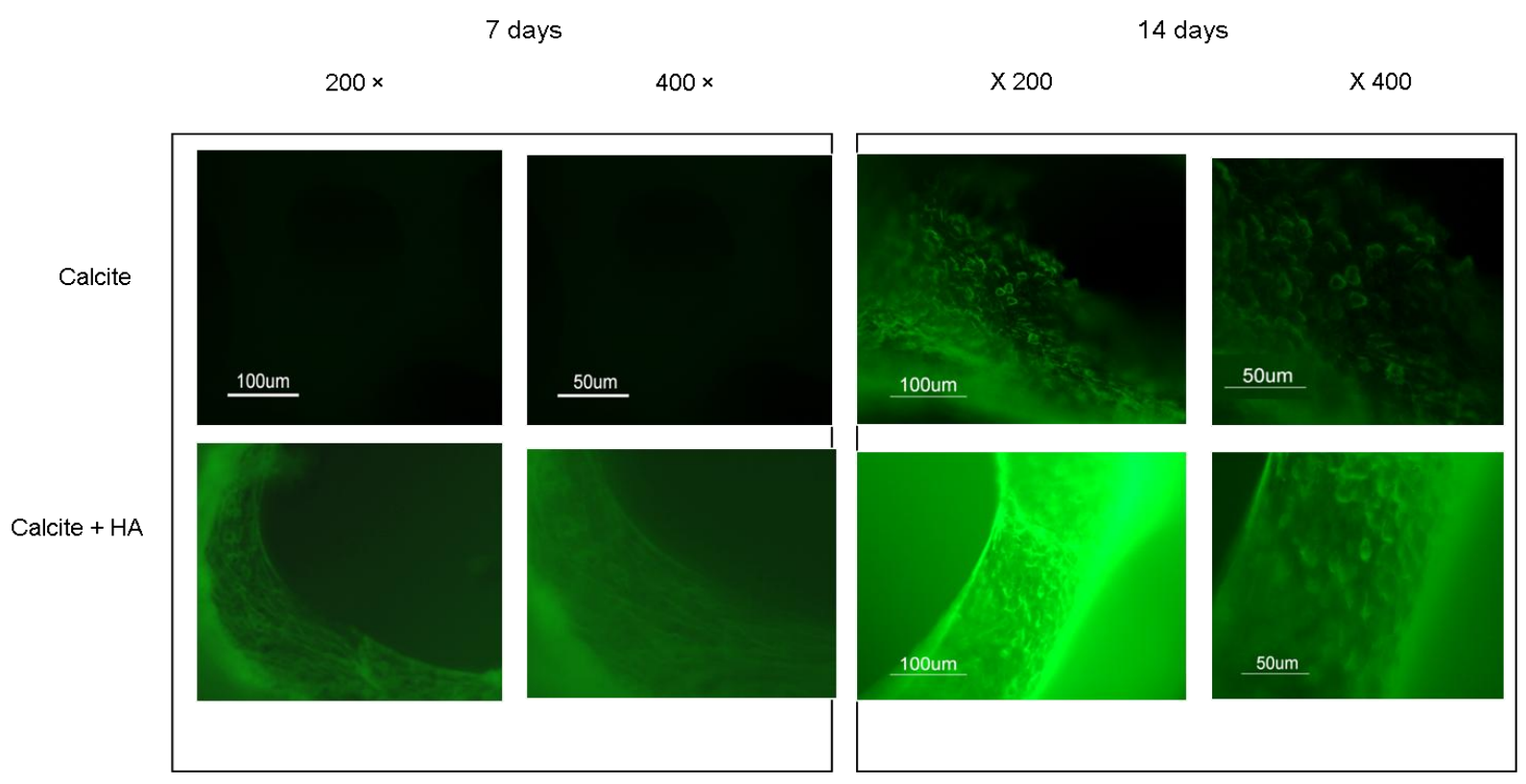

The results of immunohistochemistry staining with monoclonal antibodies against collagen I and collagen II of MCSs at 7, 14, and 21 day showed that the cells grown in the calcite culture expressed both collagen I and collagen II, indicating the heterogenic character of the tissue formed (Figure 7). Collagen I expression on aragonite tended to increase during the culture period, however, and on day 21 its expression exceeded that of collagen II, indicating that osteogenesis predominated. The addition of HA to the aragonite did not significantly change cell differentiation fates. When the MCSs were cultured on the calcite, however, collagen I expression increased while that of collagen II decreased. In contrast, cells cultured on the calcite-HA biocomplex showed much stronger collagen II than collagen I expression, a trend that increased over time, thus providing evidence that the calciteHA biocomplex promoted MSC chondrogenic differentiation.

Immunohistochemistry analysis of the expressions of the proteins collagen type I and type II indicated that the calcite culture had a heterogenic character, such that the expressions of both proteins were displayed. In contrast, in the calcite-HA culture, expression of the collagen type II protein prevailed (Figure 7). Because sulfated GAGs and collagen type II are the major indicators of tissue culture chondrogenecity, our findings reveal that the calcite-HA environment promotes the chondrogenic differentiation of MSCs. The initially enhanced expression of $N$-cadherin in the calcite-HA culture is also indicative of the dominance of chondrogenic over osteogenic differentiation (Figure 6). It could be concluded that, immobilized on the calcite surface, HA activates its receptors, particularly CD44, thus triggering their signal transduction pathways and leading to the chondrogenic differentiation of MSCs while concurrently preventing the dedifferentiation process. Previous studies reported that differentiated MSCs were able to dedifferentiate, meaning that they lost their chondrogenic phenotypes when grown in long-term culture [54]. If the chondrogenic phenotype of MSCs cultured on the calcite-HA composite is maintained in long-term culture, that implies that interactions between HA and its receptors are a major determinant in preventing MSC dedifferentiation. 
Figure 7. Immunohistochemical staining with monoclonal antibodies for the detection of collagen type I and collagen type II of MSCs cultured in calcite versus calcite-HA groups after 7, 14, and 21 day. In the calcite culture, collagen I expression increased while that of collagen II decreased over the experimental period. The tissue formed on the calcite-hyaluronan biohybrid exhibited strong collagen II and very weak collagen I expression, a result indicating that this biohybrid is better suited to the chondrogenic differentiation of MSCs.

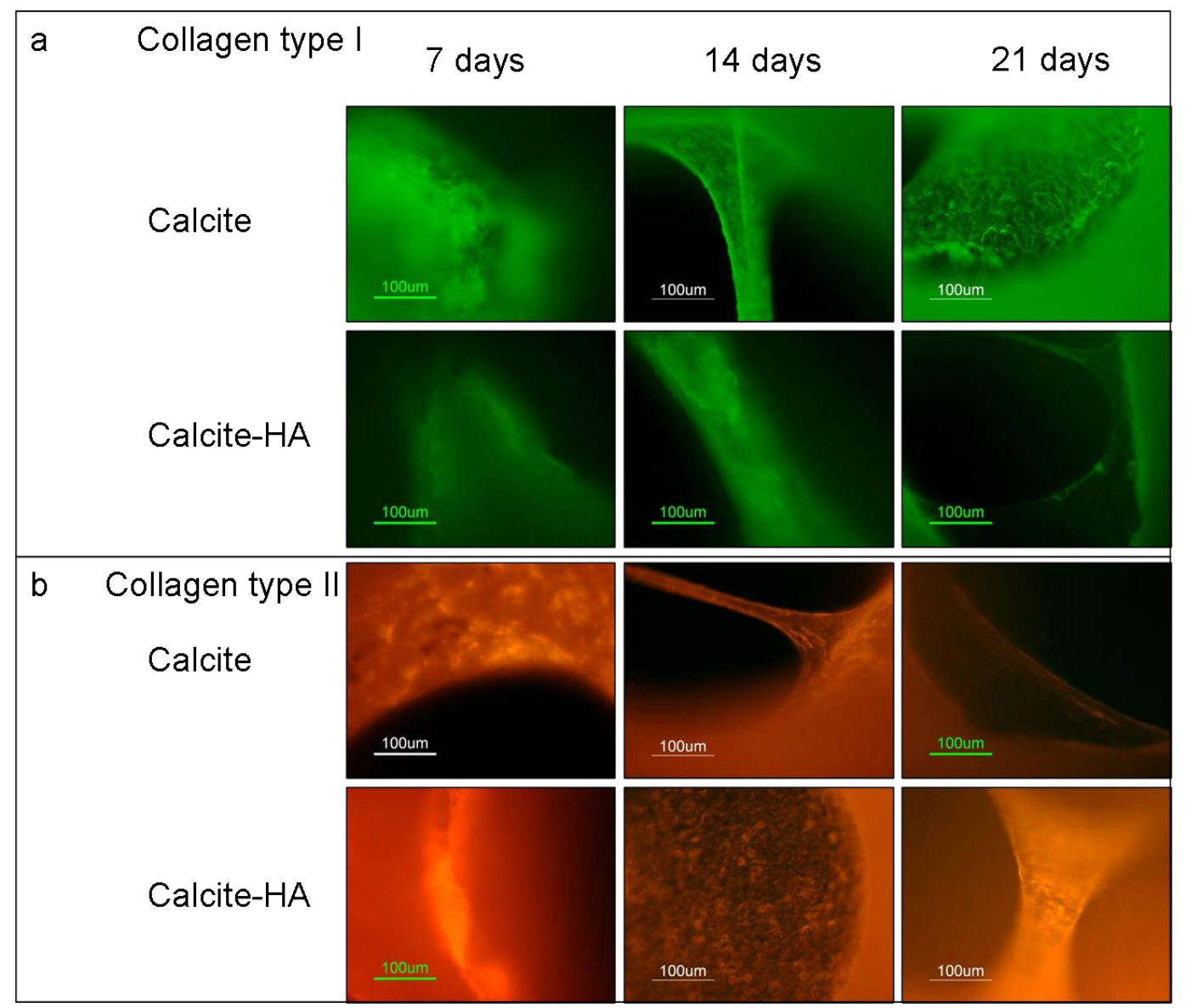

The combination of HA with synthetic polymers, such as polylactic/polyglycolic acids was intended to improve the poor biological properties of the latter [55,56]. Mixtures of HA with hydroxyapatite and calcium phosphate ceramics for developing composite biomaterials [57-61] resulted in prolonged scaffold stability and reduced degradation rates, but the composite exhibited impaired biological activity. Described here is a novel combination of non-modified HA with natural calcite that produces a biohybrid with unique biological activities.

\section{Conclusions}

This study described a new approach to the creation of a bioactive complex that supports the chondrogenic differentiation of MSCs in long-term cell cultures. The combination of HA-based hydrogel with calcium carbonate scaffold synergistically acted to initiate the process of differentiation and to maintain the chondrogenic phenotype. 
In summary, the results demonstrate that the microenvironment created at the calcite-HA interface in the three-dimensional structure promotes chondrogenic differentiation and preserves the chondrogenic phenotype of MSCs in long-term culture. After the cells have seeded, they receive the cues for proliferation or differentiation via the cell membrane molecules through which they interact with other cells, scaffold, ECM and cytokines. Cell-cell and cell-matrix interactions contribute to the final product of differentiation-the cellular phenotype and behavior. The microenvironment formed at the calcite-HA interface facilitates changes in matrix-cell and cell-cell interactions leading to changes in the differential fates of the cells and in tissue remodeling. Both HA and calcium ions are among the molecules involved in cell adhesion mechanisms, HA via the receptor CD44, and calcium ions via the $\mathrm{Ca}^{2+}$-dependent adhesion molecules cadherins. An investigation of MSC responses to changes in the environment contributes to the basic science of stem cells and can provide insights into methods of regulation and control of the differentiation processes.

\section{References}

1. Woodfield, T.B.; van Blitterswijk, C.A.; De Wijn, J.; Sims, T.J.; Hollander, A.P.; Riesle, J. Polymer scaffolds fabricated with pore-size gradients as a model for studying the zonal organization within tissue-engineered cartilage constructs. Tissue Eng. 2005, 11, 1297-1311.

2. Raghunath, J.; Rollo, J.; Sales, K.M.; Butler, P.E.; Seifalian, A.M. Biomaterials and scaffold design: key to tissue-engineering cartilage. Appl. Biochem. Biotechnol. 2007; 46, 73-84.

3. Hench, L.L.; Polak, J.M. Third-generation biomedical materials. Science 2002, 295, 1014-1017.

4. Boccaccini, A.R.; Blaker, J.J. Bioactive composite materials for tissue engineering scaffolds. Expert Rev. Med. Devices 2005, 2, 303-317.

5. Pittenger, M.F.; Mackay, A.M.; Beck, S.C.; Jaiswal, R.K.; Douglas, R.; Mosca, J.D.; Moorman, M.A.; Simonetti, D.W.; Craig, S.; Marshak, D.R. Multilineage potential of adult human mesenchymal stem cells. Science 1999, 284, 143-147.

6. Lange, C.; Schroeder, J.; Stute, N.; Lioznov, M.V.; Zander, A.R. High-potential human mesenchymal stem cells. Stem Cells Dev. 2005, 1, 70-80.

7. Bianco, P.; Riminucci, M.; Gronthos, S.; Robey, P.G. Bone marrow stromal stem cells: nature, biology, and potential applications. Stem Cells 2001, 19, 180-192.

8. Langer, R.; Vacanti, J.P. Tissue engineering. Science 1993, 260, 920-926.

9. Butler, D.L.; Goldstein, S.A.; Guilak, F. Functional tissue engineering: The role of biomechanics. J. Biomech. Eng. 2000, 122, 570-575.

10. Daculsi, G.; Laboux, O.; Malard, O.; Weiss, P. Current state of the art of biphasic calcium phosphate bioceramics. J. Mat. Sci. Mat. Med. 2003, 14, 195-200.

11. Lakes, R. Composite biomaterials. In The Biomedical Engineering Handbook, 2nd ed.; Bronzino, J.D., Ed.; CRC Press: Boca Raton, FL, USA, 2000; pp. 208-232.

12. Demers, C.; Hamdy, C.R.; Corsi, K.; Chellat, F.; Tabrizian, M.; Yahia, L. Natural coral exoskeleton as a bone graft substitute: a review. Bio-Med. Mat. Eng. 2002, 12, 15-35.

13. Vago, R. Cnidarians biomineral in tissue engineering: a review. Marine Biotechnol. 2008, 10, 343-349. 
14. Chen, F.; Chen, S.; Tao, K.; Feng, X.; Liu, Y.; Lei, D.; Mao, T. Marrow-derived osteoblasts seeded into porous natural coral to prefabricate a vascularised bone graft in the shape of a human mandibular ramus: Experimental study in rabbits. Br. J. Oral Maxillofac. Surg. 2004, 42, 532-537.

15. Vago, R. Beyond the skeleton: Cnidarian biomaterials as bioactive extracellular microenvironments for tissue engineering. Organogenesis 2008, 4, 18-22.

16. Abramovitch-Gottlib, L.; Geresh, S.; Vago, R. Biofabricated marine hydrozoan: A bioactive crystalline material promoting ossification of mesenchymal stem cells. Tissue Eng. 2006, 12, 729-739.

17. Fujita, Y.; Yamamuro, T.; Nakamura, T.; Kotani, S.; Ohtsuki, C.; Kokubo, T. The bonding behavior of calcite to bone. J. Biomed. Mat. Res. 1991, 25, 991-1003.

18. Fricain, J.C.; Bareille, R.; Ulysse, F.; Dupuy, B.; Amedee, J. Evaluation of proliferation and protein expression of human bone marrow cells cultured on coral crystallized in the aragonite of calcite form. J. Biomed. Mat. Res. 1998, 42, 96-102.

19. Gross-Aviv, T.; Astachov, L.; Kantaroving, K.; Bar, I.; Vago, R. Skeleton of Tetraclita rufotincta: a novel biomaterial for tissue engineering applications. In Biomimetic and Supramolecular Systems Research, 1st ed.; Lima, H.A., Ed.; Nova Science: Hauppauge, NY, USA, 2009; pp. 207-213.

20. Astachov, L.; Nevo, Z.; Aviv, M.; Vago, R. Crystalline calcium carbonate and hydrogels as microenvironment for stem cells. Front. Biosci. 2011, 16, 458-471.

21. Toole, B.P.; Okayama, M.; Orkin, R.W.; Yoshimura, M.; Muto, M.; Kaji, A. Developmental roles of hyaluronate and chondroitin sulfate proteoglycans. Soc. Gen. Physiol. Ser. 1977, 32, 139-154.

22. Camenisch, T.D.; McDonald, J.A. Hyaluronan: Is bigger better? Am. J. Respir. Cell Mol. Biol. 2000, 23, 431-433.

23. Knudson, C.B.; Toole, B.P. Changes in the pericellular matrix during differentiation of limb bud mesoderm. Dev. Biol. 1985, 112, 308-318.

24. Ponta, H.; Sherman, L.; Herrlich, P.A. CD44: From adhesion molecules to signalling regulators. Nature Rev. Mol. Cell Biol. 2003, 4, 33-45.

25. Toole, B.P. Hyaluronan: from extracellular glue to pericellular cue. Nature Rev. Cancer 2004, 4, 528-539.

26. Turley, E.A.; Noble, P.W.; Bourguignon, L.Y. Signaling properties of hyaluronan receptors. J. Biol. Chem. 2002, 277, 4589-4592.

27. Astachov, L.; Vago, R.; Aviv, M.; Nevo, Z. Hyaluronan and mesenchymal stem cells: From germ layer to cartilage and bone. Front. Biosci. 2011, 16, 261-276.

28. Horn, E.M.; Beaumont, M.; Shu, X.Z.; Harvey, A.; Prestwich, G.D.; Horn, K.M.; Gibson, A.R.; Preul, M.C.; Panitch, A. Influence of cross-linked hyaluronic acid hydrogels on neurite outgrowth and recovery from spinal cord injury. J. Neurosurg. Spine 2007, 6, 133-140.

29. Meszar, Z.; Felszeghy, S.; Veress, G.; Matesz, K.; Szekely, G.; Modis, L. Hyaluronan accumulates around differentiating neurons in spinal cord of chicken embryos. Brain Res. Bull. 2000, 75, 414-418.

30. Chan, C.K.; Wang ,J.; Lin, L.; Hao, Y.; Chan, S.O. Enzymatic removal of hyaluronan affects routing of axons in the mouse optic chiasm. NeuroReport 2007, 18, 1533-1538. 
31. Zavan, B.; Abatangelo, G.; Mazzoleni, F.; Bassetto, F.; Cortivo, R.; Vindigni, V. New 3D hyaluronan-based scaffold for in vitro reconstruction of the rat sciatic nerve. Neurol. Res. 2008, 30, 190-196.

32. Sakai, Y.; Matsuyama, Y.; Takahashi, K.; Sato, T.; Hattori, T.; Nakashima, S.; Ishiguro, N. New artificial nerve conduits made with photocrosslinked hyaluronic acid for peripheral nerve regeneration. Bio-Med. Mat. Eng. 2007, 17, 191-197.

33. Angele, P.; Muller, R.; Schumann, D.; Englert, C.; Zellner, J.; Johnstone, B.; Yoo, J.; Hammer, J.; Fierlbeck, J.; Angele, M.K.; Nerlich, M.; Kujat, R. Characterization of esterified hyaluronan-gelatin polymer composites suitable for chondrogenic differentiation of mesenchymal stem cells. J. Biomed. Mat. Res. A 2009, 91, 416-427.

34. Cristino, S.; Grassi, F.; Toneguzzi, S.; Piacentini, A.; Grigolo, B.; Santi, S.; Riccio, M.; Tognana, E.; Facchini, A.; Lisignoli, G. Analysis of mesenchymal stem cells grown on a three-dimensional HYAFF 11-based prototype ligament scaffold. J. Biomed. Mat. Res. A 2005, 73, $275-283$.

35. Lisignoli, G.; Cristino, S.; Piacentini, A.; Toneguzzi, S.; Grassi, F.; Cavallo, C.; Zini, N.; Solimando, L.; Maraldi, N.M.; Facchini, A. Cellular and molecular events during chondrogenesis of human mesenchymal stromal cells grown in a three-dimensional hyaluronan based scaffold. Biomaterials 2005, 26, 5677-5686.

36. Baier Leach, J.; Bivens, K.A.; Patrick, C.W., Jr.; Schmidt, C.E. Photocrosslinked hyaluronic acid hydrogels: Natural, biodegradable tissue engineering scaffolds. Biotechnol. Bioeng. 2003, 82, 578-589.

37. Milella, E.; Brescia, E.; Massaro, C.; Ramires, P.A.; Miglietta, M.R.; Fiori, V.; Aversa, P. Physico-chemical properties and degradability of non-woven hyaluronan benzylic esters as tissue engineering scaffolds. Biomaterials 2002, 23, 1053-1063.

38. Kito, H.; Matsuda, T. Biocompatible coatings for luminal and outer surfaces of small-caliber artificial grafts. J. Biomed. Mat. Res. 1996, 30, 321-330.

39. Aigner, J.; Tegeler, J.; Hutzler, P.; Campoccia, D.; Pavesio, A.; Hammer, C.; Kastenbauer, E.; Naumann, A. Cartilage tissue engineering with novel nonwoven structured biomaterial based on hyaluronic acid benzyl ester. J. Biomed. Mat. Res. 1998, 42, 172-181.

40. Schmittgen, T.D.; Livak, K.J. Analyzing real-time PCR data by the comparative CT method. Nature Protoc. 2008, 3, 1101-1108.

41. Stockwell, R. Biology of Cartilage Cells, 1st ed.; Cambridge University Press: Cambridge, UK, 1979.

42. Pilloni, A.; Bernard, G.W. The effect of hyaluronan on mouse intramembranous osteogenesis in vitro. Cell Tissue Res. 1998, 294, 323-333.

43. Zou, X.; Li, H.; Chen, L.; Baatrup, A.; Bunger, C.; Lind, M. Stimulation of porcine bone marrow stromal cells by hyaluronan, dexamethasone and rhBMP-2. Biomaterials 2004, 25, 5375-5385.

44. Huang, L.; Cheng, Y.Y.; Koo, P.L.; Lee, K.M.; Qin, L.; Cheng, J.C.; Kumta, S.M. The effect of hyaluronan on osteoblast proliferation and differentiation in rat calvarial-derived cell cultures. J. Biomed. Mat. Res. A 2003, 66, 880-884. 
45. Liu, C.M.; Yu, C.H.; Chang, C.H.; Hsu, C.C.; Huang, L.L. Hyaluronan substratum holds mesenchymal stem cells in slow-cycling mode by prolonging G1 phase. Cell Tissue Res. 2008, 334, 435-443.

46. Pure, E.; Assoian, R.K. Rheostatic signaling by CD44 and hyaluronan. Cell. Signal. 2009, 21, 651-655.

47. Lesley, J.; English, N.; Charles, C.; Hyman, R. The role of the CD44 cytoplasmic and transmembrane domains in constitutive and inducible hyaluronan binding. Eur. J. Immunol. 2000, 30, 245-253.

48. Takeda, M.; Ogino, S.; Umemoto, R.; Sakakura, M.; Kajiwara, M.; Sugahara, K.N.; Hayasaka, H.; Miyasaka, M.; Terasawa, H.; Shimada, I. Ligand-induced structural changes of the CD44 hyaluronan-binding domain revealed by NMR. J. Biol. Chem. 2006, 281, 40089-40095.

49. Lefebvre, V.; Behringer, R.R.; de Crombrugghe, B. L-Sox5, Sox6 and Sox 9 control essential steps of the chondrocyte differentiation pathway. Osteoarthr. Cartil. 2001, 9, S69-S75.

50. Ng, L.J.; Wheatley, S.; Muscat, G.E.; Conway-Campbell, J.; Bowles, J.; Wright, E.; Bell, D.M.; Tam, P.P.; Cheah, K.S.; Koopman, P. SOX9 binds DNA, activates transcription, and coexpresses with type II collagen during chondrogenesis in the mouse. Dev. Biol. 1997, 183, 108-121.

51. Wright, E.; Hargrave, M.R.; Christiansen, J.; Cooper, L.; Kun, J.; Evans, T.; Gangadharan, U.; Greenfield, A.; Koopman, P. The Sry-related gene Sox9 is expressed during chondrogenesis in mouse embryos. Nat. Genet. 1995, 9, 15-20.

52. Murakami, S.; Kan, M.; McKeehan, W.L.; de Crombrugghe, B. Up-regulation of the chondrogenic Sox 9 gene by fibroblast growth factors is mediated by the mitogen-activated protein kinase pathway. Proc. Natl. Acad. Sci. USA 2000, 97, 1113-1118.

53. Javed, A.; Afzal, F.; Bae, J.S.; Gutierrez, S.; Zaidi, K.; Pratap, J.; van Wijnen, A.J.; Stein, J.L.; Stein, G.S.; Lian, J.B. Specific residues of RUNX2 are obligatory for formation of BMP2-induced RUNX2-SMAD complex to promote osteoblast differentiation. Cell Tissue Organs 2009, 189, 133-137.

54. Galle, J.; Bader, A.; Hepp, P.; Grill, W.; Fuchs, B.; Kas, J.A.; Krinner, A.; Marquass, B.; Müller, K.; Schiller, J.; et al. Mesenchymal stem cells in cartilage repair: state of the art and methods to monitor cell growth, differentiation and cartilage regeneration. Curr. Med. Chem. 2010, 17, 2274-2291.

55. Palumbo, F.S.; Pitarresi, G.; Mandracchia, D.; Tripodo, G.; Giammona, G. New graft copolymers of hyaluronic acid and polylactic acid: synthesis and characterization. Carbohydr. Polym. 2006, 66, 379-385.

56. Baumann, M.D.; Kang, C.E.; Tator, C.H.; Shoichet, M.S. Intrathecal delivery of a polymeric nanocomposite hydrogel after spinal cord injury. Biomaterials 2010, 31, 7631-7639.

57. Bakos, D.; Soldan, M.; Hernandez-Fuentes, I. Hydroxyapatite-collagen-hyaluronic acid composite. Biomaterials 1999, 20, 191-195.

58. Gao, J.; Dennis, J.E.; Solchaga, L.A.; Awadallah, A.S.; Goldberg, V.M.; Caplan, A.I. Tissue-engineered fabrication of an osteochondral composite graft using rat bone marrow-derived mesenchymal stem cells. Tissue Eng. 2001, 7, 363-371. 
59. Gao, J.; Dennis, J.E.; Solchaga, L.A.; Goldberg, V.M.; Caplan, A.I. Repair of osteochondral defect with tissue-engineered two-phase composite material of injectable calcium phosphate and hyaluronan sponge. Tissue Eng. 2002, 8, 827-837.

60. Radice, M.; Brun, P.; Cortivo, R.; Scapinelli, R.; Battaliard, C.; Abatangelo, G. Hyaluronan-based biopolymers as delivery vehicles for bone-marrow-derived mesenchymal progenitors. J. Biomed. Mat. Res. 2000, 50, 101-109.

61. Solchaga, L.A.; Yoo, J.U.; Lundberg, M.; Dennis, J.E.; Huibregtse, B.A.; Goldberg, V.M.; Caplan, A.I. Hyaluronan-based polymers in the treatment of osteochondral defects. J. Orthop. Res. 2000, 18, 773-780.

(C) 2012 by the authors; licensee MDPI, Basel, Switzerland. This article is an open access article distributed under the terms and conditions of the Creative Commons Attribution license (http://creativecommons.org/licenses/by/3.0/). 